Article

\title{
A Class of Control Strategies for Energy Internet Considering System Robustness and Operation Cost Optimization
}

\author{
Haochen Hua ${ }^{\mathbb{D}}$, Chuantong Hao, Yuchao Qin and Junwei Cao * (D) \\ Research Institute of Information Technology, Tsinghua University, Beijing 100084, China; \\ hhua@tsinghua.edu.cn (H.H.); hct16@mails.tsinghua.edu.cn (C.H.); qinyc17@mails.tsinghua.edu.cn (Y.Q.) \\ * Correspondence: jcao@tsinghua.edu.cn; Tel.: +86-010-6277-2260
}

Received: 28 May 2018; Accepted: 14 June 2018; Published: 18 June 2018

\begin{abstract}
Aiming at restructuring the conventional energy delivery infrastructure, the concept of energy Internet (EI) has become popular in recent years. Outstanding benefits from an EI include openness, robustness and reliability. Most of the existing literatures focus on the conceptual design of EI and are lack of theoretical investigation on developing specific control strategies for the operation of EI. In this paper, a class of control strategies for EI considering system robustness and operation cost optimization is investigated. Focusing on the EI system robustness issue, system parameter uncertainty, external disturbance and tracking error are taken into consideration, and we formulate such robust control issue as a structure specified mixed $\mathrm{H}_{2} / \mathrm{H}_{\infty}$ control problem. When formulating the operation cost optimization problem, three aspects are considered: realizing the bottom-up energy management principle, reducing the cost involved by power delivery from power grid (PG) to microgrid (MG), and avoiding the situation of over-control. We highlight that this is the very first time that the above targets are considered simultaneously in the field of EI. The integrated control issue is considered in frequency domain and is solved by a particle swarm optimization (PSO) algorithm. Simulation results show that our proposed method achieves the targets.
\end{abstract}

Keywords: energy Internet; microgrids; mixed $H_{2} / H_{\infty}$ control; optimal control; robust control

\section{Introduction}

Over the last few decades, global warming, energy crises and ecological issues have promoted the research of renewable power generation and distributed energy networks [1,2]. For the integration of a variety of distributed energy resources (DERs), MGs play an important role [3,4]. In MGs, the produced power by renewable energy sources (RESs) including photovoltaic (PV) units and wind turbine generators (WTGs) has disadvantages such as low inertia, uncertainty, and dynamic complexity [5,6]. In addition, the output power of electrical loads depends on residents' power usage customs and varies stochastically [7]. In MGs, to alleviate power imbalance, and to regulate voltage/frequency oscillation, the control of MGs is a subject of both practical and theoretical importance [8].

Following the principle of smart grids specializing in informatization and intellectualization of the existing power systems [9], and to solve the aforementioned challenges within the scenario of multiple interconnected MGs, the new concept of EI is proposed [10] and is considered to be an upgraded version of smart grid [11]. The definition and interpretation of EI are briefly outlined as follows. Inspired by cores of the Internet, the EI can be viewed as an Internet-style solution to energy related problems by integrating bi-directional flows of information and power [12]. Within the scope of EI, energy production and consumption are coordinated decentrally, such that open and peer-to-peer energy sharing is enabled. An iterative balance among power generation, storage and consumption 
shall be achieved in real time. In an EI scenario, multiple MGs are interconnected via energy router (ERs) [13], which are also known as energy hubs [14], or power routers [15]. Different from the top-down mode in the existing power systems, bottom-up is a fundamental energy management principle in EI [11]. To achieve such target, each individual MG in EI shall be able to regulate the power deviation with its local energy storage, generation and consumption devices with priority. If power balance in any MG is hard to be achieved autonomously, other MGs can send/absorb electrical energy to/from it via ERs, helping achieve its local power balance [11]. By scheduling and routing across energy cells in EI efficiently, secure and reliable power delivery can be achieved [12].

In the field of EI, when multiple MGs are interconnected, the related energy management and control issues are more complicated than the ones in isolated MG. Optimal control problems regarding energy management have been popular. For example, coordinated optimal control algorithm for smart distribution management system in multiple MGs is investigated in [16]. Applying a multi-objective stochastic optimization approach to solve the optimal energy management issues in MGs has been reported in [17]. To achieve an optimized operation of an off-grid MG, nonlinear droop relations are implemented in [18]. In [19], optimal control strategy for MG under both off-grid and grid-connected mode has been studied. Distributed control and optimization in DC MGs has been investigated in [20].

On the other hand, robust control problems in the fields of MG and EI have received much attention in the past few years. For instance, in [21], both $H_{\infty}$ and $\mu$-synthesis approaches are utilized to regulate AC bus frequency deviations in an off-grid MG. A descriptor system $H_{\infty}$ approach has been applied in autonomous MGs to improve signal stability [22]. In [23], the issue of voltage control in an EI scenario is formulated as a non-fragile robust $H_{\infty}$ control problem regarding an uncertain stochastic nonlinear system, and it is solved via a linear matrix inequality approach. Robust $H_{\infty}$ load-frequency control (LFC) in a hybrid distributed generation system has been studied in [24].

For different optimal control problems mentioned in e.g., [16-20], a variety of optimization targets are considered to formulate the $\mathrm{H}_{2}$ performance. For robust control problems discussed in e.g., [21-24], $H_{\infty}$ performance has been focused. When both $H_{2}$ and $H_{\infty}$ performances are considered simultaneously, the associated issues are called mixed $H_{2} / H_{\infty}$ control problems. The applications of mixed $\mathrm{H}_{2} / \mathrm{H}_{\infty}$ control theory in the field of MG have attracted much attention, and significant advances on this topic have been made. Some related research outputs are illustrated as follows. For an islanded $\mathrm{AC}$ MG, the problems of operation cost optimization and frequency regulation are formulated as a mixed $\mathrm{H}_{2} / \mathrm{H}_{\infty}$ control problem in deterministic systems in [25]. In [26], the robust mixed $H_{2} / H_{\infty}$ voltage control strategy is designed to improve signal stability and fault ride through capability for an islanded MG. It has been shown that the fixed structure mixed $\mathrm{H}_{2} / \mathrm{H}_{\infty}$ control technique can be used to obtain a coordinated vehicle-to-grid control and frequency controller for robust LFC in a smart grid [27]. A robust mixed $\mathrm{H}_{2} / \mathrm{H}_{\infty}$ based LFC of a deregulated power system including superconducting magnetic energy storage has been proposed in [28]. For other works regarding the application of mixed $\mathrm{H}_{2} / \mathrm{H}_{\infty}$ control into MGs, readers can refer to [29,30], etc. It is notable that, although a mixed $\mathrm{H}_{2} / \mathrm{H}_{\infty}$ control technique has been widely used in conventional power systems, there has been little work applying such control schemes into the field of EI.

When multiple MGs are interconnected via ERs, no matter if they are grid-connected or not, there are a variety of optimal and robust control problems worth considering. In this paper, we are concerned with the problems of controller design for EI considering system robustness and operation cost optimization. A series-shaped EI is studied in this article. Within the considered EI scenario, three MGs are interconnected successively and one MG has access to the main PG. In MGs, we assume that there exist the following elements: PV units, WTGs, fuel cells (FCs), hydrogen tanks (HTs), electrolyzers (ESs), micro-turbines (MTs), heat pumps (HPs), plug-in hybrid electric vehicles (PHEVs), diesel engine generators (DEGs), battery energy storage (BES) devices, flywheel energy storage (FES) devices, ERs and normal loads. The system of EI is formulated via a frequency domain approach. When the above robust and optimal control targets are considered simultaneously, PI controllers are utilized in ESs, MTs, HPs, PHEV, DEGs, the transmission line between $\mathrm{MG}_{1}$ and $\mathrm{MG}_{2}$, and the transmission 
line between $\mathrm{MG}_{2}$ and $\mathrm{MG}_{3}$. Then, we solve such control problem via a PSO algorithm [31]. Next, simulations demonstrate the usefulness and effectiveness of our proposed controller.

The importance and contribution of this work can be outlined as follows. As is mentioned above, some existing works only investigate either optimization of operation cost and energy management (e.g., [16-20]), or robustness against internal instability and external disturbances (e.g., [21-24]) of MG systems. In this paper, this is the very first time that both two aspects are considered simultaneously in the field of EI, rather than in conventional energy systems. The regulation of system robustness and tracking performance are formulated as a mixed $H_{2} / H_{\infty}$ control problem. Our work can be viewed as an extension as well as a generalized version for the ones focusing on single islanded or grid-connected MG. Comparing this paper with some existing ones adopting a time domain approach (e.g., $[7,23,25])$, our work formulated in the frequency domain has the advantage that it is convenient to be implemented in actual dynamic situations. With the proposed controller, the following targets are achieved simultaneously: (1) the system robustness against parameter uncertainty and external disturbance is achieved; (2) the tracking error is a controller to a relative low level; (3) the bottom-up energy management principle is achieved, such that an autonomous power balance in each MG is achieved with priority; (4) the cost involved by power delivery from PG to MG has been considered; (5) the controllable devices in MGs are utilized rationally, and the situation of over-control is avoided; (6) considering different preferences of the system manager, the importance of each control target can be adjusted by changing the size of its corresponding weighting coefficient; and (7) in simulation results, it is shown that the proposed controller performs better than the conventional ones do. It is highlighted that our work is of both theoretical and practical importance.

The rest of the paper is organized as follows: Section 2 introduces the system modelling. The control problem is formulated and solved in Section 3. Section 4 presents some simulations. Finally, some conclusions are drawn in Section 5.

\section{System Modelling}

In this section, we focus on a series-shaped EI system with three ERs. Every component of the system is modelled with first order transfer function in frequency domain. Then, an explicit mathematical control system is obtained.

\subsection{The Scenario of an EI}

A series-shaped $\mathrm{EI}$ is studied in this article. $\mathrm{MG}_{1}, \mathrm{MG}_{2}$ and $\mathrm{MG}_{3}$ are connected successively. In addition, we assume that $\mathrm{MG}_{1}$ is connected to PG. All of the ERs are designed to be based on $\mathrm{AC}$ bus lines. Figure 1 shows the topology of the studied EI system.

In $\mathrm{MG}_{1}, \mathrm{PV}$ units, WTGs, loads, FCs, MTs, HTs and ESs are connected to $\mathrm{ER}_{1}$ via converters. The main power supply in $\mathrm{MG}_{1}$ is assumed to reply on power output by PV units and WTGs. If the power generation by PV units and WTGs is not enough for power consumption in $\mathrm{MG}_{1}$, highly controllable power generators such as MTs and FCs are utilized to fill the power supply-demand gap. Whenever there exists superfluous energy in $\mathrm{MG}_{1}, \mathrm{ESs}$ are used to covert electric energy into hydrogen, which is stored in HTs. Hydrogen can be used to generate power by FCs. Normal loads such as housings or factories have access to $\mathrm{ER}_{1}$ as well. In addition, $\mathrm{MG}_{1}$ is designed to have a connection to $\mathrm{PG}$ and $\mathrm{ER}_{2}$.

$\mathrm{MG}_{2}$ is designed to have access to different components in $\mathrm{MG}_{1}$, except for the requisite local loads. WTGs are utilized as the major power generators in $\mathrm{MG}_{2}$. We assume that, in residential communities and cluster charging stations, large amounts of highly controllable HPs and PHEVs are connected to $\mathrm{ER}_{2}$. When the power generation is larger than consumption in $\mathrm{MG}_{2}$, the access of HPs and PHEVs shall be able to ensure the power balance of $\mathrm{MG}_{2}$. Whenever $\mathrm{MG}_{2}$ suffers from a lack of electricity, power can be transmitted from $M_{1}$ and $M_{3}$ via $E_{1}$ and $E_{2}$, respectively.

We assume that $M_{3}$ is only connected with $M_{2}$ and these two MGs are far away from each other. Thus, the dynamic response of power transmission line is slower than that of local devices in 
$\mathrm{MG}_{3}$. Assuming that $\mathrm{MG}_{3}$ is sensitive to power deviation, responsive energy storage devices such as BES and FES devices are essential to keep its power balance. In addition, another kind of highly controllable power generator, DEGs, have connections with $\mathrm{MG}_{3}$. PV units and loads are also included in $\mathrm{MG}_{3}$.

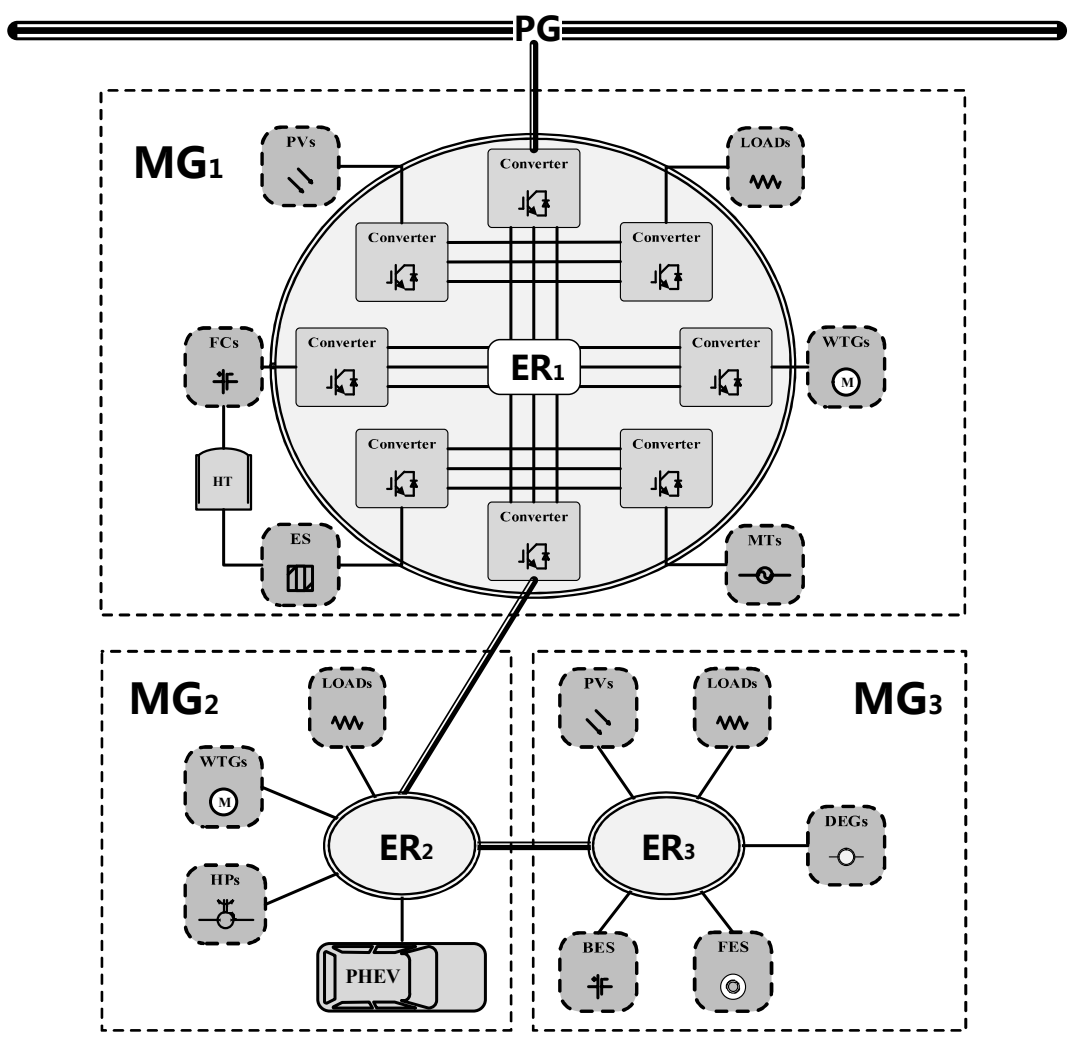

Figure 1. The studied series-shaped energy Internet (EI) system.

\subsection{Linearized Block Diagram}

Power balance equation of $\mathrm{MG}_{1}, \mathrm{MG}_{2}$ and $\mathrm{MG}_{3}$ can be expressed in Equations (1), (2) and (3), respectively:

$$
\begin{gathered}
\Delta P_{1}=P_{P V 1}+P_{W T G 1}+P_{F C}+P_{M T}+P_{P G}-\left(P_{E S}+P_{E R 12}+P_{L O A D 1}\right), \\
\Delta P_{2}=P_{W T G 2}+P_{E R 12}-\left(P_{P H E V}+P_{H P}+P_{E R 23}+P_{L O A D 2}\right), \\
\Delta P_{3}=P_{P V 3}+P_{D E G}+P_{E R 23}-P_{L O A D 3} \pm\left(P_{B E S}+P_{F E S}\right) .
\end{gathered}
$$

In this paper, $\Delta P_{E S}$ and $\Delta P_{F C}$ are approximated by a first order transfer function [32], as is shown in Equations (4) and (5):

$$
\begin{aligned}
& \Delta P_{E S}=\frac{K_{E S}}{1+T_{E S} S} \Delta f_{1}, \\
& \Delta P_{F C}=\frac{K_{F C}}{1+T_{F C} S} \Delta f_{1} .
\end{aligned}
$$

Considering the linear power versus frequency droop characteristics, $\Delta P_{M T}$ is obtained by Equation (6):

$$
\Delta P_{M T}=-\frac{1}{K_{M T}} \Delta f_{1}
$$


Relative phase angle [rad] between PG and $\mathrm{ER}_{1}$ is obtained by Equation (7):

$$
\theta=2 \pi f_{0} \int \Delta f_{1} d t
$$

Let us denote $\theta$ as the relative phase angle and $X_{P G}$ as line reactance. Consequently, $P_{P G}$ is given by Equation (8):

$$
P_{P G}=\frac{\sin \theta}{X_{P G}} .
$$

Based on previous studies $[23,33], P_{H P}, P_{P H E V}$ and $P_{E R 12}$ are obtained by the following equations:

$$
\begin{gathered}
P_{H P}=\frac{K_{H P}}{1+T_{H P S}} K_{H P C} \Delta f_{2}, \\
P_{P H E V}=\frac{K_{P H E V}}{1+T_{P H E V S}} K_{P H E V C} \Delta f_{2}, \\
P_{E R 12}=\frac{b_{E R 12}}{1+T_{E R 12 S}} K_{E R 12 C} \Delta f_{2} .
\end{gathered}
$$

We assume that BES and FES devices are equipped with internal controllers and respond to the AC bus frequency deviation [21]. $P_{B E S}$ and $P_{F E S}$ can be obtained by:

$$
\begin{aligned}
& P_{B E S}=\frac{1}{1+T_{B E S S}} \Delta f_{3}, \\
& P_{F E S}=\frac{1}{1+T_{F E S} S} \Delta f_{3} .
\end{aligned}
$$

$P_{D E G}$ and $P_{E R 23}$ are obtained by Equations (14) and (15):

$$
\begin{gathered}
P_{D E G}=\frac{1}{1+T_{D E G} s} K_{D E G C} \Delta f_{3}, \\
P_{E R 12}=\frac{b_{E R 23}}{1+T_{E R 23} s} K_{E R 23 C} \Delta f_{3} .
\end{gathered}
$$

Rapid or oversized power deviation may lead to instability of the AC bus frequency oscillation in MGs. With desired control strategies in $\mathrm{MG}_{1}, \mathrm{MG}_{2}$ and $\mathrm{MG}_{3}$, power balance in these $\mathrm{MGs}$ can be achieved, and instability of $\Delta f_{1}, \Delta f_{2}$ and $\Delta f_{3}$ can be avoided. In this paper, PI controllers are utilized on ESs, MTs, HPs, PHEV, DEGs, the transmission line between $\mathrm{MG}_{1}$ and $\mathrm{MG}_{2}$, and the transmission line between $\mathrm{MG}_{2}$ and $\mathrm{MG}_{3}$. Then, we have:

$$
\left\{\begin{array}{c}
\Delta P_{E S C}=K_{E S C}(s) \cdot P_{P G} \\
\Delta P_{M T C}=K_{M T C}(s) \cdot P_{P G} \\
U_{E R 12}=K_{E R 12 C}(s) \cdot \Delta f_{2} \\
U_{H P}=K_{H P C}(s) \cdot \Delta f_{2} \\
U_{P H E V}=K_{P H E V C}(s) \cdot \Delta f_{2} \\
U_{D E G}=K_{D E G C}(s) \cdot \Delta f_{3} \\
U_{E R 23}=K_{E R 23 C}(s) \cdot \Delta f_{3}
\end{array}\right.
$$


where

$$
\left\{\begin{aligned}
K_{E S C}(s) & =K_{P_{E S}}+K_{I_{E S}} / s, \\
K_{M T C}(s) & =K_{P_{M T}}+K_{I_{M T}} / s, \\
K_{E R 12 C}(s) & =K_{P_{E R 12}}+K_{I_{E R 12}} / s, \\
K_{H P C}(s) & =K_{P_{H P}}+K_{I_{H P}} / s, \\
K_{P H E V C}(s) & =K_{P_{P H E V}}+K_{I_{P H E V}} / s, \\
K_{D E G C}(s) & =K_{P_{D E G}}+K_{I_{D E G}} / s, \\
K_{E R 23 C}(s) & =K_{P_{E R 23}}+K_{I_{E R 23}} / s .
\end{aligned}\right.
$$

According to Equations (1), (4)-(8) and (16), the linearized block diagram of $\mathrm{MG}_{1}$ is illustrated in Figure 2. According to Equations (2), (9)-(11) and (16), the linearized block diagram of $\mathrm{MG}_{2}$ is illustrated in Figure 3. According to Equations (3), (12)-(16), the linearized block diagram of $\mathrm{MG}_{3}$ is illustrated in Figure 4.

Based on inverse Laplace transformation and the frequency-domain block diagram in Figures 2-4, we are able to transform the studied EI system from Equations (1)-(16) into an explicit mathematical control system:

$$
\left\{\begin{array}{l}
\dot{x}=A x+B u \\
y=C x+D u
\end{array}\right.
$$

where $x$ is state vector, $y$ is output vector and $u$ is control output, expressed as:

$$
\begin{aligned}
& x=\left[\begin{array}{llllllllll}
\Delta P_{E S} & P_{P G} & \Delta f_{1} & P_{H P} & P_{P H E V} & P_{E R 12} & \Delta f_{2} & P_{D E G} & P_{E R 23} & \Delta f_{3}
\end{array}\right]^{\prime}, \\
& y=\left[\begin{array}{lll}
\Delta f_{1} & \Delta f_{2} & \Delta f_{3}
\end{array}\right]^{\prime},
\end{aligned}
$$

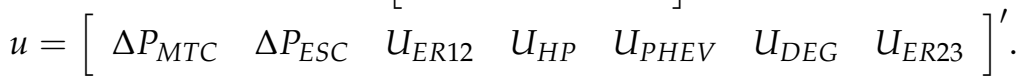

The EI system Equation (16) is a multi-input-multi-output (MIMO) control system with the nominal plant $G$ and the controller $K$.

We highlight that various topologies of EI (e.g., series-shaped, annular-shaped, star-shaped, etc.) can be formulated into mathematical systems in the form of Equation (17). Hence, the investigation to series-shaped EI and the obtained results can be extended and applied into generalized EI scenarios.

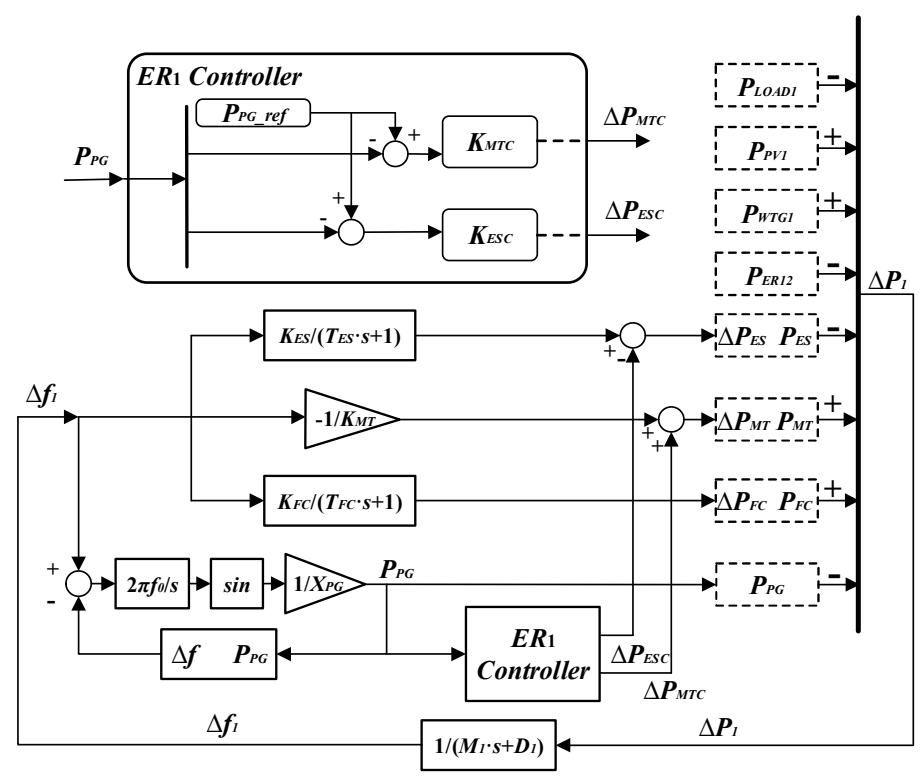

Figure 2. The linearized block diagram of the first microgrid $\left(\mathrm{MG}_{1}\right)$. 


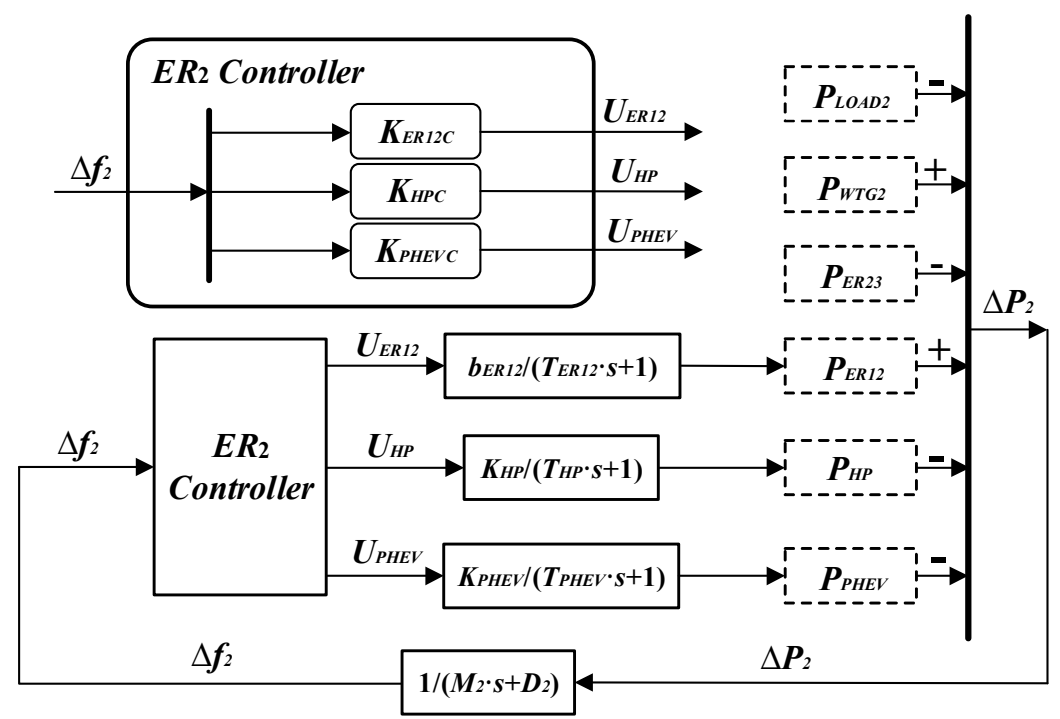

Figure 3. The linearized block diagram of the second microgrid $\left(\mathrm{MG}_{2}\right)$.

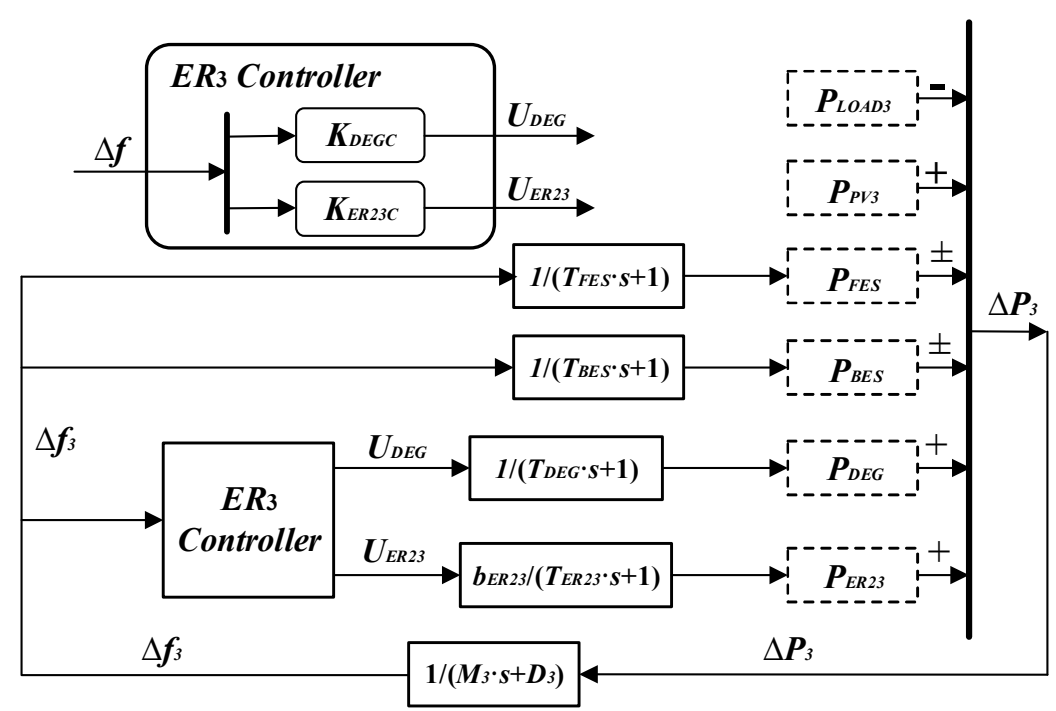

Figure 4. The linearized block diagram of the third microgrid $\left(\mathrm{MG}_{3}\right)$.

\section{Problem Formulation and Solution.}

In this section, the EI system robustness issue is formulated as the structure specified mixed $\mathrm{H}_{2} / \mathrm{H}_{\infty}$ control problem, whereas the operation cost management issue in EI is formulated as a multi-objective optimization problem. We consider such mixed robust and optimal control targets simultaneously, and we solve this control problem via a PSO algorithm [31].

\subsection{Robust Control for EI}

For a practical system, parameter measurement error and various power oscillation are inevitable, which brings system uncertainties $[25,26]$. In addition, power generated by PV units depends heavily on the condition of light intensity, and power generated by WTGs depends heavily on the condition of wind power. Moreover, varieties of power consumption devices can change the dissipation of power. Thus, external disturbance to the system shall be taken into consideration when designing robust controllers. 
Considering a MIMO control system with external disturbances and system uncertainties, a nominal plant of the studied EI is denoted as $G$, and $K$ represents the proposed controller. $r(t), e(t)$, $u(t), d(t)$ and $y(t)$ stand for reference input, tracking error, control output, external disturbance and system output, respectively. Inverse output multiplicative uncertainty [34], denoted as $\Delta$, is utilized to model system uncertainties. System robustness and tracking performance are formulated as $H_{\infty}$ and $H_{2}$ performance, respectively. The structure specified mixed $H_{2} / H_{\infty}$ control system is shown in Figure 5.

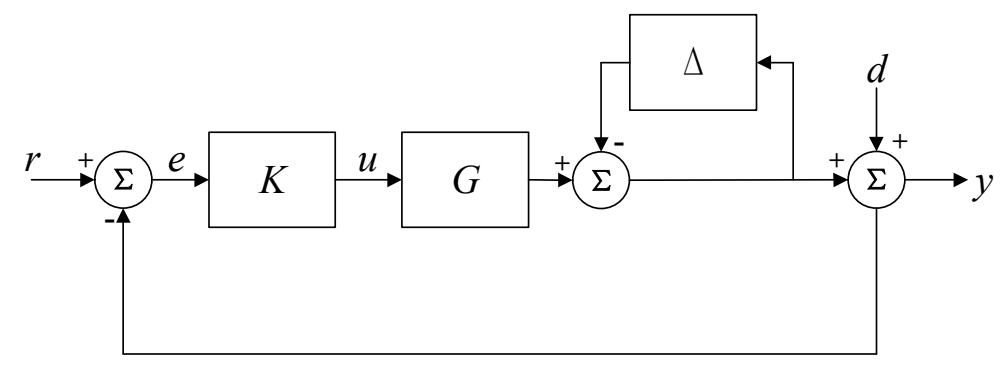

Figure 5. The control system of the studied EI with external disturbance and system uncertainties.

Based on the small gain theorem [35], a system with multiplicative uncertainties is stable if and only if Equation (18) holds:

$$
\left\|\Delta \cdot(I+G K)^{-1}\right\|_{\infty}<1,
$$

where $\|\cdot\|_{\infty}$ refers to the usual $\mathcal{L}_{\infty}[0, \infty)$ norm. Thus, we have

$$
\|\Delta\|_{\infty}<\frac{1}{\left\|(I+G K)^{-1}\right\|_{\infty}} .
$$

Based on Equation (19), the size of the system uncertainties is obtained by $1 /\left\|(I+G K)^{-1}\right\|_{\infty}$, which also implies the robust stability margin against the system uncertainties. Hence, the controlled system's robust stability is maximized when $\left\|(I+G K)^{-1}\right\|_{\infty}$ is minimized. The robust $H_{\infty}$ control objective function is formulated as $J_{\infty}$ :

$$
J_{\infty}=\left\|(I+G K)^{-1}\right\|_{\infty}
$$

In addition to robust stability and disturbance attenuation, tracking performance should be optimized as well [36]. The objective function of tracking error is formulated as the integral of the squared error:

$$
J_{e}=\int_{0}^{\infty} e^{\prime}(t) e(t) d t=\|E(s)\|_{2}^{2}
$$

where $\|\cdot\|_{2}$ stands for the usual $\mathcal{L}_{2}[0, \infty)$ norm, and $e(t)=r(t)-y(t)$ is the tracking error, figured out by the inverse Laplace transformation of $E(s)$ with $\Delta=0$ and $d(t)=0$ :

$$
E(s)=(I+G K)^{-1} R(s) .
$$

Thereby, considering system robustness, the structure specified mixed $\mathrm{H}_{2} / \mathrm{H}_{\infty}$ control objective function is obtained by $J_{1}$ given as follows:

$$
J_{1}=J_{e}+J_{\infty}
$$

\subsection{Operation Cost Optimization}

The operation cost of the studied system includes varieties of aspects among which three objective functions are identified below. 
The first objective is to regulate the power transmission between every two connected MGs to a relatively low level. According to the bottom-up principle for EI, the autonomous power balance in each MG shall be achieved preferably. Equivalently, power transmission $P_{E R 12}$ and $P_{E R 23}$ are expected to be kept within a relatively small amount. According to the linearized block diagrams of $\mathrm{MG}_{2}$ and $\mathrm{MG}_{3}$, the objective function can be formulated as $J_{\text {Trans }}$ :

$$
J_{\text {Trans }}=\left\|\frac{b_{E R 12}}{1+T_{E R 12 S}} K_{E R 12 C}\right\|_{2}^{2}+\left\|\frac{b_{E R 23}}{1+T_{E R 23 S}} K_{E R 23 C}\right\|_{2}^{2} .
$$

The second objective function is focused on reducing the cost involved by power delivery from PG to MG. Within the scope of EI, the autonomous power generation is preferably nominated as the main energy supply source in a MG $[10,11]$. If a MG relies heavily on power exchange with PG to maintain its operation, it will not only violate the energy management principles of the EI, but also lead to expensive electricity purchasing cost. When economic benefit is concerned, both electricity price and the amount of power transmitted from PG to MG shall be considered. Normally, the electricity price varies over time by hours [37]. In this article, we focus on a time slot no more than one hour during which the electricity price is assumed to be constant. The economic cost involved by power delivery from PG to MG can be formulated as the 2-norm square of the product of electricity price and power transmitted from $P G$ to $M_{1}$ :

$$
J_{\text {Cost }}=\| \text { Price }_{e} \cdot \frac{\sin \left(\frac{2 \pi f_{0}}{s}\right)}{X_{P G}} \|_{2}^{2},
$$

where Price $_{e}$ is the electricity price based on real-time electricity market. Thus, Equation (25) can be viewed as the second objective function.

The third objective function aims at reducing the additional cost involved by all the controllers utilized in the studied EI system. Although a stronger controller may lead to better performance, the probability of over-control is greatly increased. The situation of over-control will trigger additional costs for the operation of EI. The cost function $J_{C t l}$ is utilized to estimate the cost involved by the controllers:

$$
J_{C t l}=\sum_{k \in \Omega}\|k\|_{2}^{2}
$$

where $\Omega$ is the set of all the controllers in the studied EI system. According to Section 2, we have $\Omega=\left\{K_{E S C}, K_{M T C}, K_{H P C}, K_{P H E V C}, K_{D E G C}, K_{E R 12 C}, K_{E R 23 C}\right\}$. By minimizing $J_{C t l}$, the situation of over-control can be avoided effectively.

Taking three objective Equations (24)-(26) and the preference of the decision maker into consideration, the system operation cost function is formulated by:

$$
J_{2}=\omega_{1} J_{\text {Trans }}+\omega_{2} J_{\text {Cost }}+\omega_{3} J_{C t l}
$$

where $\omega_{1}, \omega_{2}$ and $\omega_{3}$ are weighting coefficients.

\subsection{The Mixed Control Objective}

The mixed control target is described by the sum of the structure specified mixed $\mathrm{H}_{2} / \mathrm{H}_{\infty}$ control objective function and the system cost optimization control objective, defined as

$$
J=J_{1}+J_{2} .
$$


In this paper, our control target is to minimize $J$, subject to:

$$
\left\{\begin{array}{c}
K_{P_{\min }}<K_{P}<K_{P_{\max }} \\
K_{I_{\min }}<K_{I}<K_{I_{\max }}
\end{array} .\right.
$$

In (29), $K_{P} \in \Phi_{P}$ and $K_{I} \in \Phi_{I} . \quad \Phi_{P}$ is the set of all the proportion parameters, and $\Phi_{P}=\left\{K_{P_{E S}}, K_{P_{M T}}, K_{P_{E R 12}}, K_{P_{H P}}, K_{P_{P H E V}}, K_{P_{D E G}}, K_{P_{E R 23}}\right\} . \Phi_{I}$ is the set of all the integral parameters, and $\Phi_{I}=\left\{K_{I_{E S}}, K_{I_{M T}}, K_{I_{E R 12}}, K_{I_{H P}}, K_{I_{P H E V}}, K_{I_{D E G}}, K_{I_{E R 23}}\right\} . K_{P_{\min }}$ and $K_{P_{\max }}$ are the minimum and maximum parameters of the proportion part of the controllers; $K_{I_{\min }}$ and $K_{I_{\max }}$ are the minimum and maximum parameters of the integral part of the controllers.

\subsection{Solution to the Studied Control Problem}

It is notable that the control problem described in Equations (28)-(29) can be solved by the PSO algorithm [31]. The flowchart of the PSO algorithm is shown in Figure 6, and the detailed implementation process is introduced as follows:

1. Decide the numbers and the range of movement of the particles. Initialize them with random velocities and positions.

2. Calculate the fitness value based on Equation (28) with the help of MATLAB (R2014b, MathWorks, Natick, MA, USA) $\mu$-Analysis and Synthesis Toolbox.

3. Calculate the best previously visited position pbest and the global best position gbest.

4. Update the velocity and position of particle with the following equations:

$$
\begin{gathered}
v_{i+1}=w \cdot v_{i}+c_{1} \cdot \text { rand }_{1} \cdot\left(\text { pbest }_{i}-x_{i}\right)+c_{2} \cdot \text { rand }_{2} \cdot\left(\text { gbest }_{i}-x_{i}\right), \\
x_{i+1}=x_{i}+v_{i+1}, \\
w=w_{\max }-\frac{w_{\text {max }}-w_{\min }}{\text { iter }_{\text {max }}} \text { iter. }
\end{gathered}
$$

5. If iter $_{\text {max }}$ is arrived, stop the circulation. Otherwise, go to process 2.

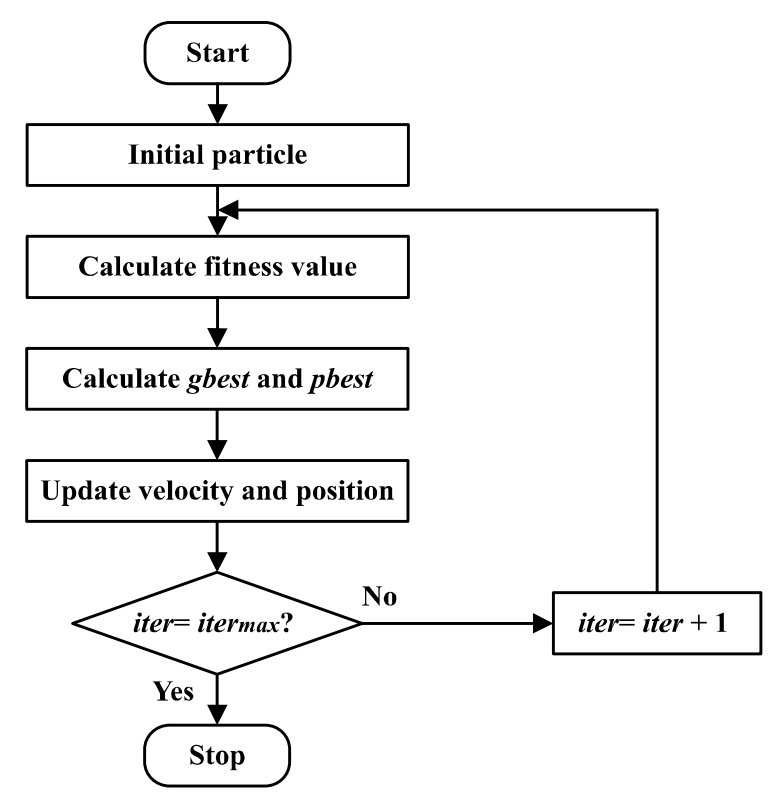

Figure 6. The flowchart of the particle swarm optimization (PSO) algorithm.

The simulation results are demonstrated in the next section. 


\section{Simulation Results and Analysis}

In this section, some simulation results and analysis are given to verify the effectiveness of the proposed controller compared with the conventional ones.

\subsection{Simulation Results under the Proposed Controller}

According to data in [21], [32] and [33], system parameters are given in Table 1. We assume that these parameters are valid for one hour only. In the next couple of hours, the values of system parameters shall be different and should be re-estimated. In this sense, our proposed method can be applied to any time period of a day without essential difficulty. For tracking performance, the reference input $R(s)$ in Equation (22) is chosen to be 1/ $(s+5)$. The parameters of PSO algorithm are: swarm size $=50 ;$ maximum iteration $=30 ; c_{1}=0.2 ; c_{2}=0.2 ; w_{\min }=0.4$ and $w_{\max }=0.9$. According to the simulation results in Figure 7 , the value of the optimized objective function is 18.3267 .

The proposed mixed $\mathrm{H}_{2} / \mathrm{H}_{\infty}$ controller is:

$$
\left\{\begin{array}{c}
K_{E S C}(s)=0.1246+0.2710 / s \\
K_{M T C}(s)=0.3056+0.4100 / s \\
K_{E R 12 C}(s)=0.4206+0.2710 / s \\
K_{H P C}(s)=0.6666+0.2571 / s \\
K_{P H E V C}(s)=0.3326+0.2948 / s \\
K_{D E G C}(s)=0.1000+0.1000 / s \\
K_{E R 23 C}(s)=0.7008+0.3066 / s
\end{array}\right.
$$

As is shown in Figure 8, the power generation by PV units and WTGs, as well as the power consumption of loads in the studied EI system, are assumed to be random in the investigated time period, simulated by forecasted models in [32].

Table 1. System parameters.

\begin{tabular}{cccccc}
\hline Parameters & Value & Parameters & Value & Parameters & Value \\
\hline$M_{1}$ & 10 & $K_{E S}$ & 100 & $K_{M T}$ & 0.04 \\
$D_{1}$ & 1 & $T_{E S}(s)$ & 60 & $T_{D E G}(s)$ & 2 \\
$M_{2}$ & 15 & $b_{E R 12}$ & 10 & $b_{E R 23}$ & 10 \\
$D_{2}$ & 2 & $T_{E R 12}(s)$ & 1.15 & $T_{E R 23}(s)$ & 1.15 \\
$M_{3}$ & 20 & $X_{P G}$ & 0.072 & $T_{B E S}(s)$ & 0.15 \\
$D_{3}$ & 1.5 & $f_{0}(H z)$ & 50 & $T_{F E S}(s)$ & 0.12 \\
$K_{H P}$ & 10 & $K_{P H E V}$ & 10 & - & - \\
$T_{H P}(s)$ & 0.2 & $T_{P H E V}(s)$ & 0.3 & - & - \\
\hline
\end{tabular}

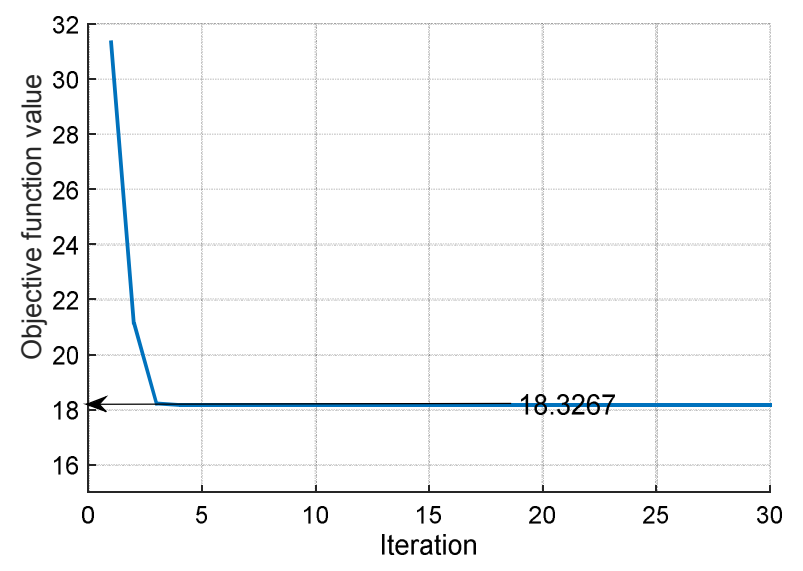

Figure 7. Objective function value. 


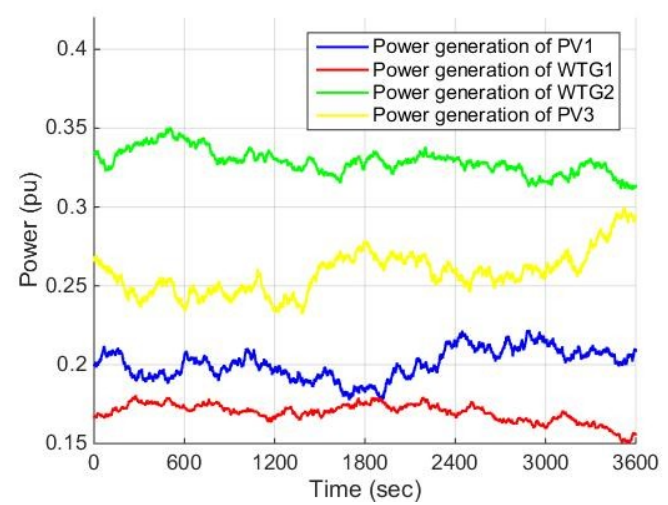

(a)

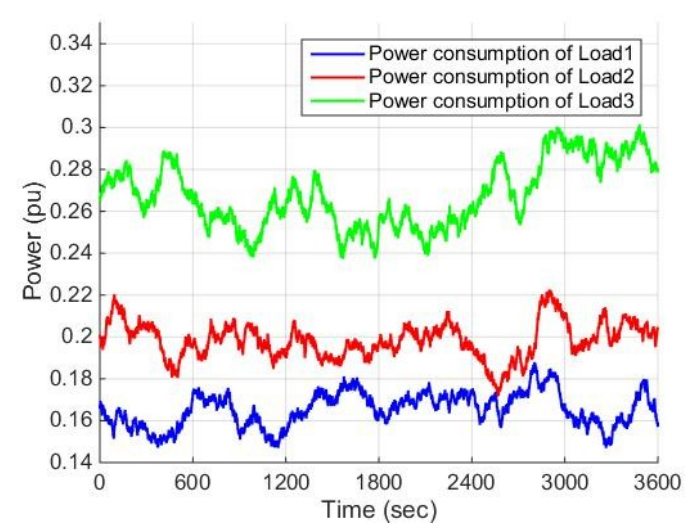

(b)

Figure 8. Local power generation and consumption; (a) power generation of photovoltaic (PV) units and wind turbine generator (WTGs); (b) power consumption of loads.

The effect of the proposed method is compared with that of the conventional ones. Conventional methods include using only robust control, which minimizes $J_{1}$ in Equation (23) subject to Equation (29) and using only optimal control, which minimizes $J_{2}$ in Equation (27) subject to Equation (29).

\subsection{Comparing the Proposed Controller with the Optimal Controller}

Let the conventional method be only using optimal control strategies, which minimizes $J_{2}$ in Equation (27) subject to Equation (29). In this subsection, the parameter uncertainty is represented by a $50 \%$ increase of the original system parameters in Table 1, whereas a sudden increase of load power in three MGs $\left(10 \%\right.$ increase of $\left.P_{L O A D 1}, P_{L O A D 2}, P_{L O A D 3}\right)$ is implemented as external disturbances.

The controlled frequency deviation of $\mathrm{MG}_{1}$ obtained by both the proposed method and the conventional method are illustrated in Figure 9 including the following four situations: (a) without external disturbance or system parameter uncertainties; (b) with external disturbance only; (c) with system parameter uncertainties only; and (d) with both external disturbance and system parameter uncertainties. The frequency deviation of $\mathrm{MG}_{1}$ is relatively small, and the difference of the control effect of the proposed method and the conventional method is not obvious, which are due to the connection of $\mathrm{MG}_{1}$ to $\mathrm{PG}$.

Frequency deviations of $\mathrm{MG}_{2}$ and $\mathrm{MG}_{3}$ without disturbance or uncertainties are illustrated in Figure 10. Obviously, the proposed method can stabilize the frequency of $A C$ bus in $M_{2}$ and $\mathrm{MG}_{3}$ more efficiently. When only the external disturbance is considered, according to Figure 11, the proposed method has several advantages: the response speed is faster, the overshoot is smaller, and the transition period is shorter than the conventional method. When only system parameter uncertainty is considered, the frequency deviations of $\mathrm{MG}_{2}$ and $\mathrm{MG}_{3}$ are illustrated in Figure 12. The results show the effectiveness of the proposed controller. Moreover, under both external disturbance and system uncertainties, the studied EI system shows better performance with the proposed method, as is shown in Figure 13. 


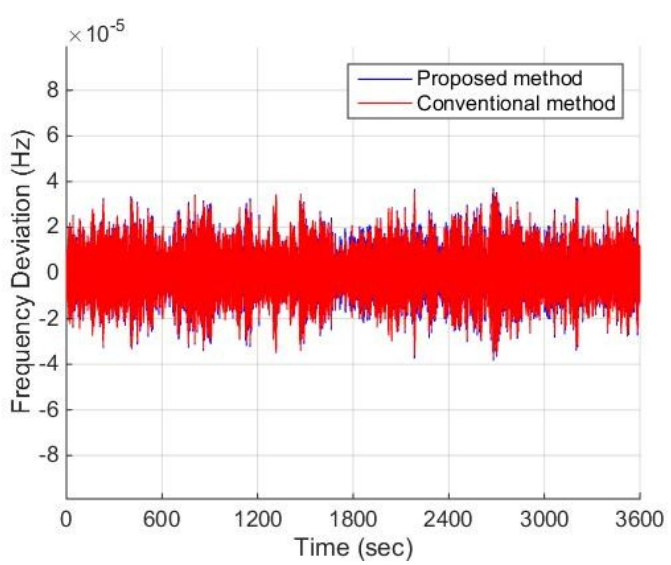

(a)

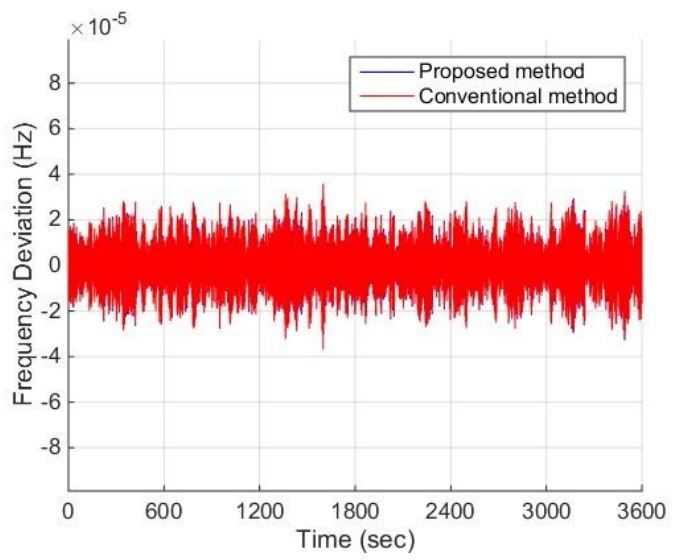

(c)

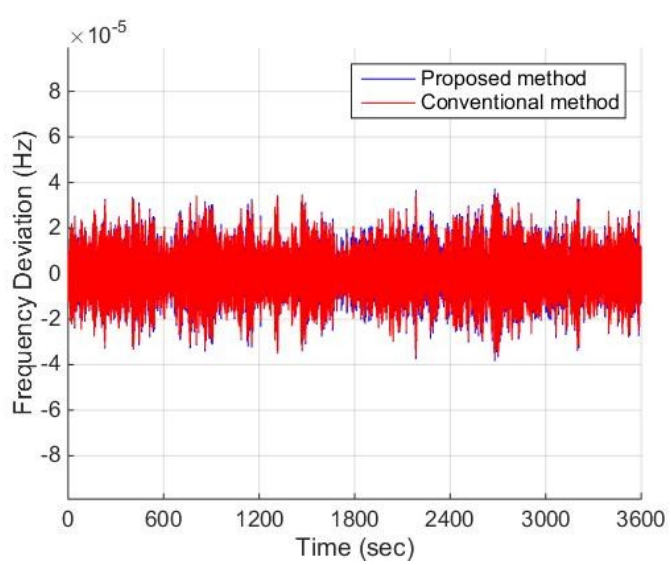

(b)

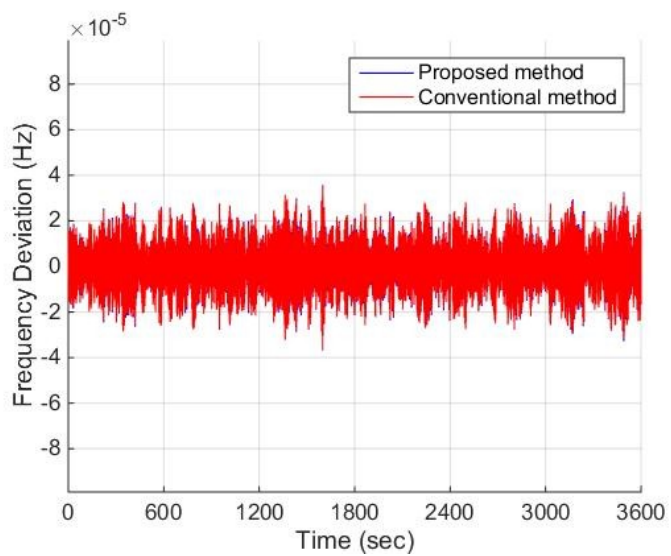

(d)

Figure 9. Frequency deviation of $\mathrm{MG}_{1}$ : (a) without disturbance or uncertainties; (b) with external disturbance; (c) with system parameter uncertainties; and (d) with external both disturbance and system parameter uncertainties.

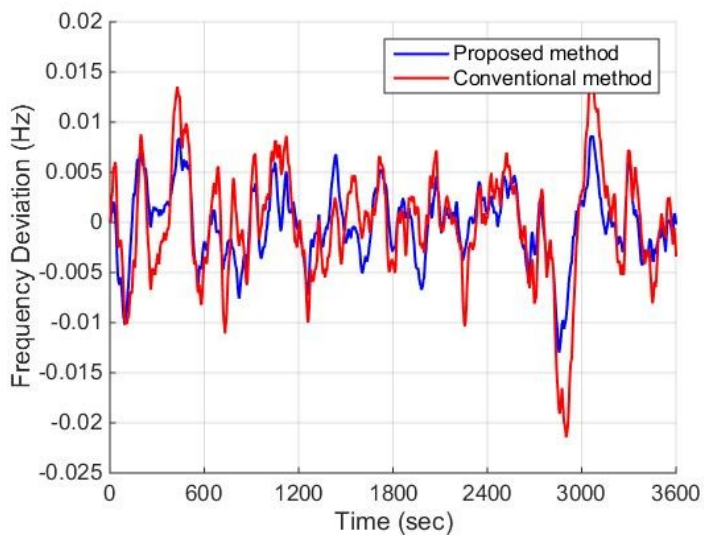

(a)

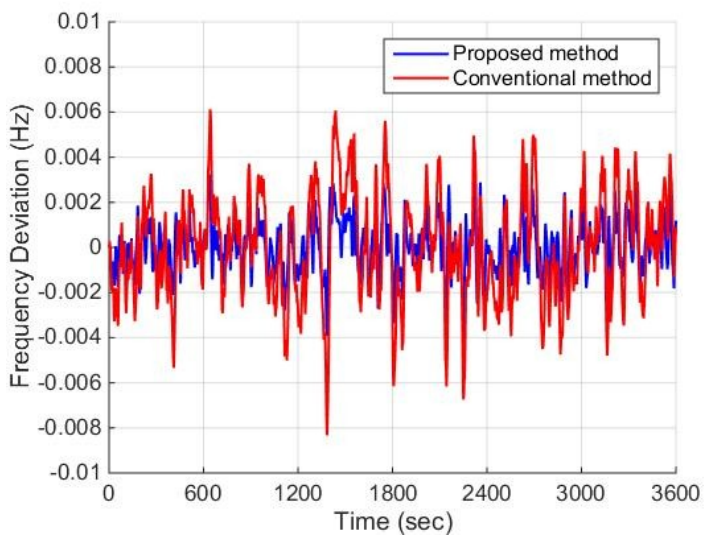

(b)

Figure 10. Frequency deviation without disturbance or uncertainties: (a) $\mathrm{MG}_{2} ;(\mathbf{b}) \mathrm{MG}_{3}$. 


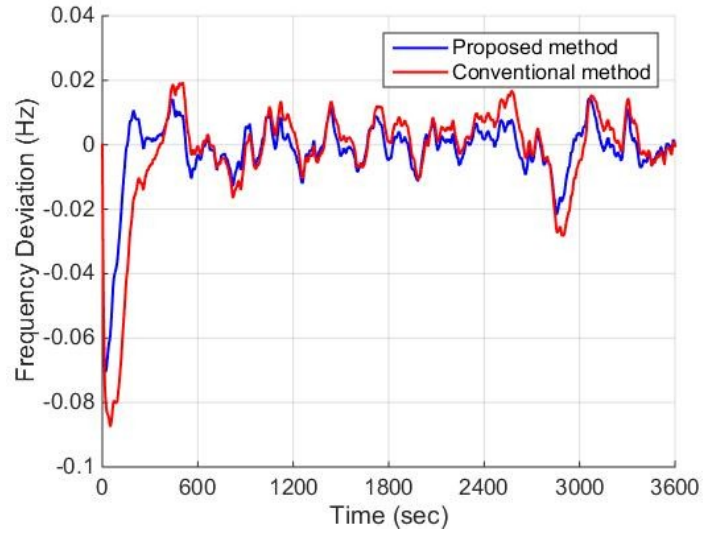

(a)

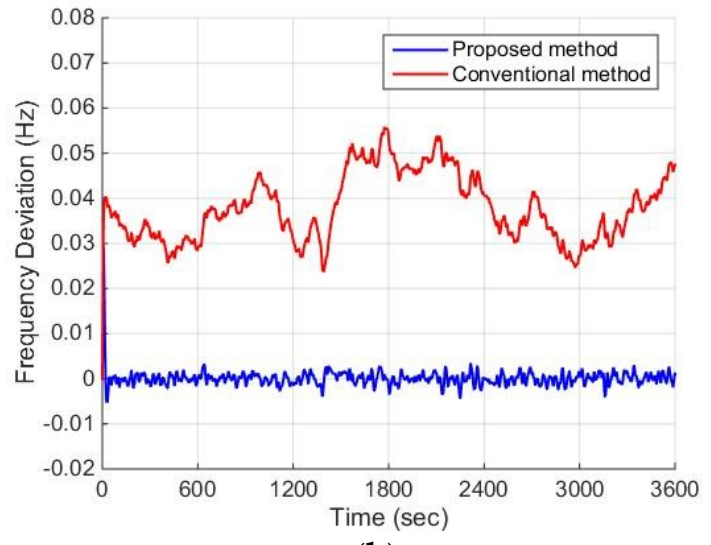

(b)

Figure 11. Frequency deviation with external disturbance: (a) $\mathrm{MG}_{2}$; (b) $\mathrm{MG}_{3}$.

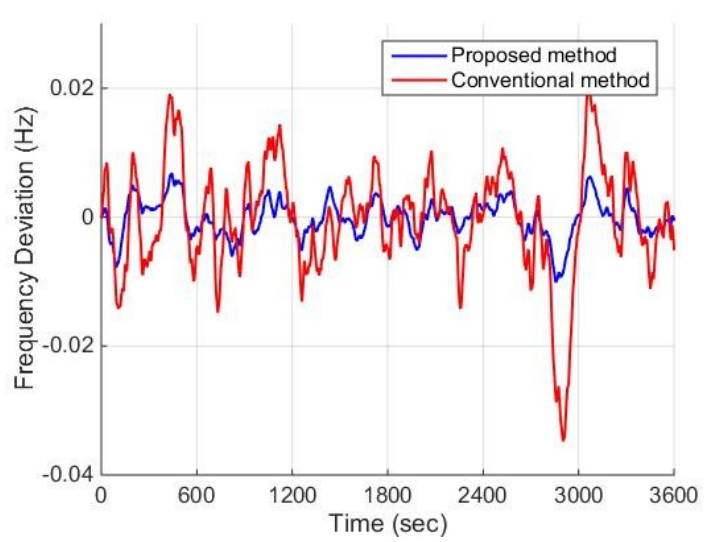

(a)

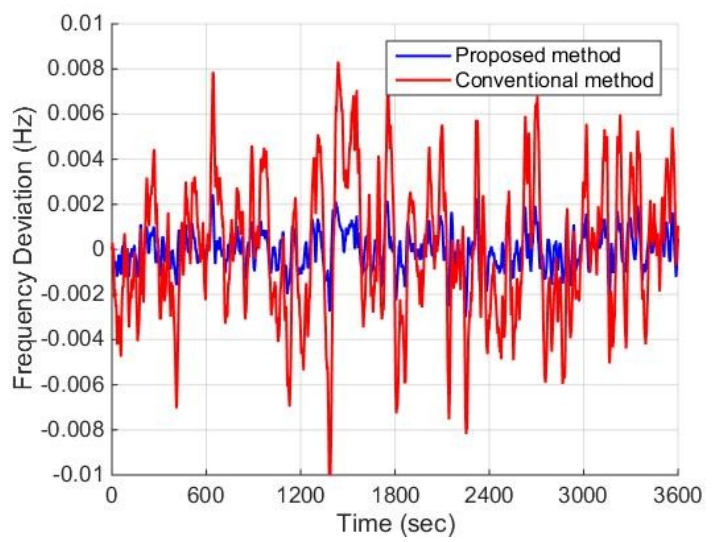

(b)

Figure 12. Frequency deviation with system parameter uncertainties: (a) $\mathrm{MG}_{2}$; (b) $\mathrm{MG}_{3}$.

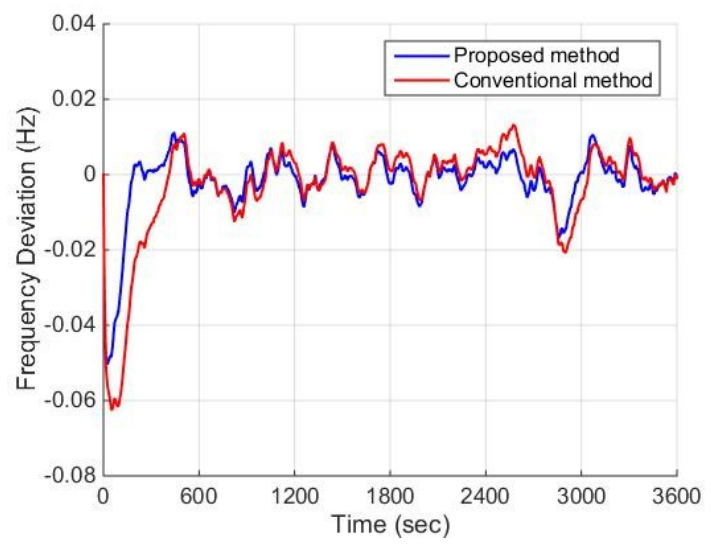

(a)

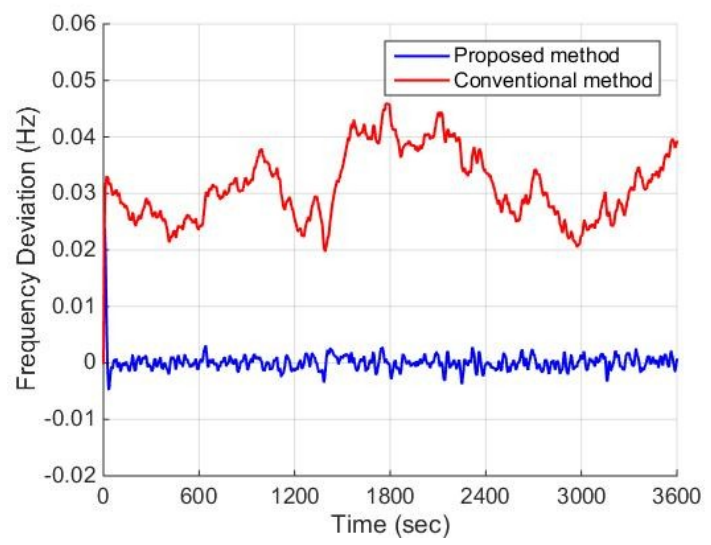

(b)

Figure 13. Frequency deviation with external disturbance and system parameter uncertainties: (a) $\mathrm{MG}_{2}$; (b) $\mathrm{MG}_{3}$.

\subsection{Comparing the Proposed Controller with the Robust Controller}

Let the conventional method be only using robust control strategies $J_{1}$ in Equation (23) subject to Equation (29). 
Figure 14 shows the power transmission between two adjacent MGs under the proposed controller and the conventional robust controller. Power transmission between PG and $\mathrm{MG}_{1}$ is illustrated in Figure 15. It is obvious that, using the proposed method, the transmission power between two adjacent MGs and that between PG and $\mathrm{MG}_{1}$ can be reduced effectively.

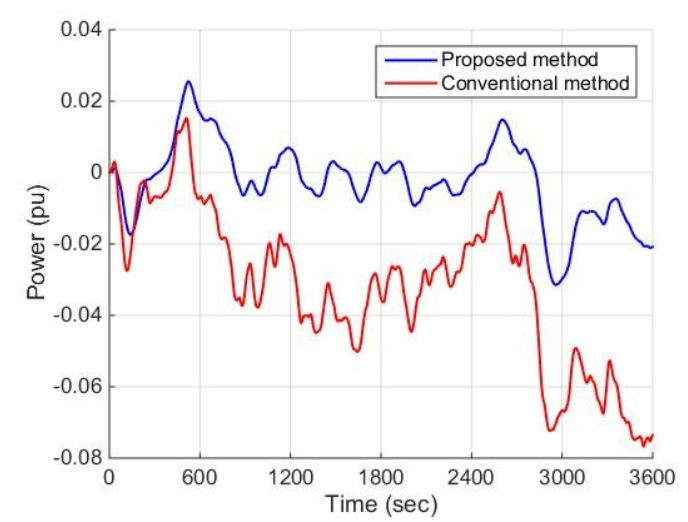

(a)

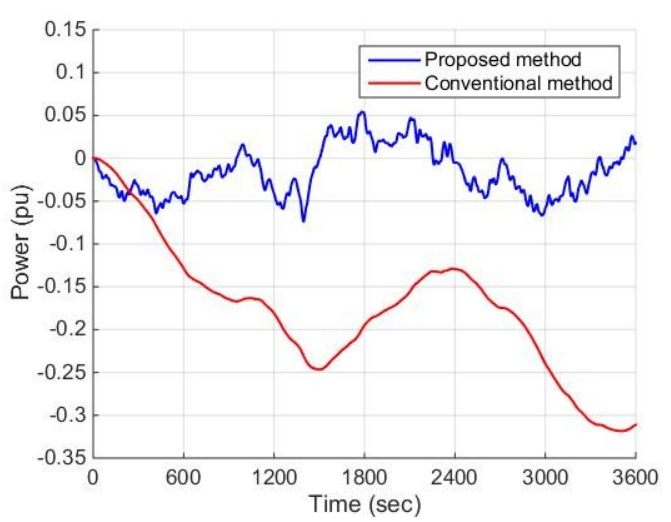

(b)

Figure 14. Power transmission between two adjacent MGs. (a) power transmission between $\mathrm{MG}_{1}$ and $\mathrm{MG}_{2} ;(\mathbf{b})$ power transmission between $\mathrm{MG}_{2}$ and $\mathrm{MG}_{3}$.

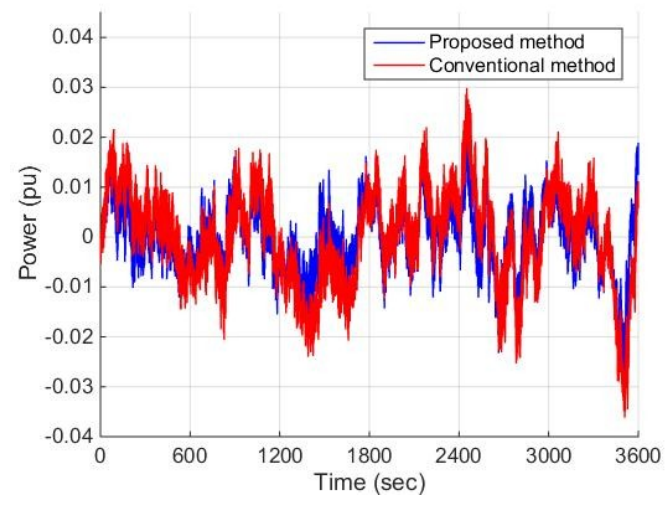

Figure 15. Power transmission between power grid (PG) and $\mathrm{MG}_{1}$.

\subsection{Some More Case Studeis}

To show the impact of different weights on the objective function, two more cases are studied. The weight of a certain objective function can reflect the tendency of decision makers.

In Case 1, we assume that the physical distance between the interconnected MGs is long, leading to relatively high power transmission cost between MGs. Thus, the main energy exchange is preferably to be achieved between PG and MGs. In Case 2, decision makers are more inclined to reduce energy exchange with PG and control the whole EI system through the power flow between MGs.

A technique that combines the weighted sum method and the rank order centroid method [37] is utilized to determine the weights. The relative importance of the three objectives is reflected by the values of the weights, given by:

$$
\omega_{i}=\frac{1}{N} \sum_{k=i}^{N} \frac{1}{k^{\prime}}, \quad i=1,2 \ldots N
$$


In our considered system, there are three MGs in total. Thus, $N=3$. Two cases with different weights are studied as follows: in Case 1, we choose $\omega_{1}=0.6110, \omega_{2}=0.2778, \omega_{3}=0.1112$, whereas, in Case 2, we choose $\omega_{1}=0.2778, \omega_{2}=0.6110, \omega_{3}=0.1112$.

With the proposed method, the simulated results are illustrated in Figure 16.

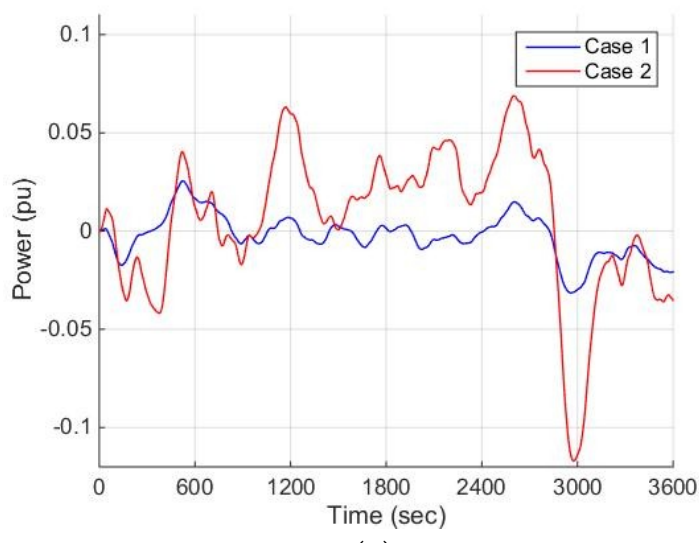

(a)

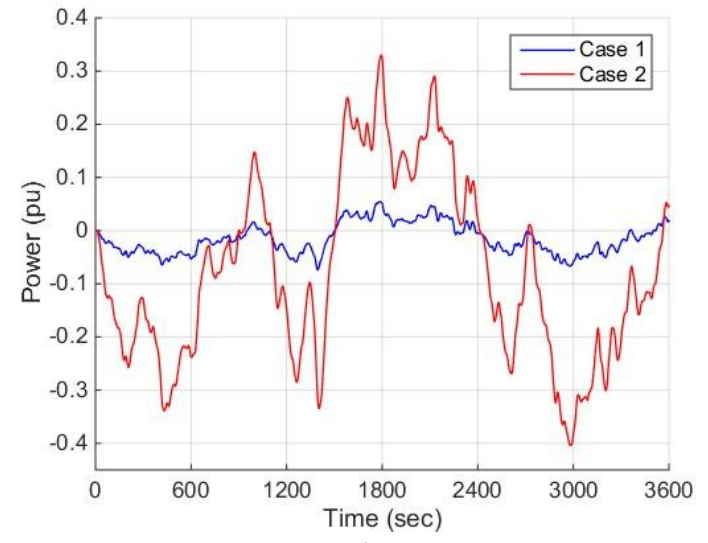

(b)

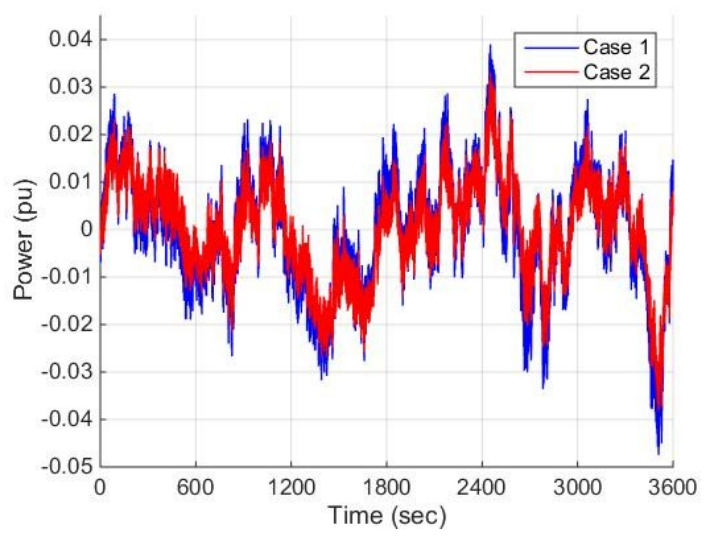

(c)

Figure 16. Power transmission under Case 1 and Case 2: (a) between $\mathrm{MG}_{1}$ and $\mathrm{MG}_{2}$; (b) between $\mathrm{MG}_{2}$ and $\mathrm{MG}_{3} ;(\mathbf{c})$ between $\mathrm{PG}$ and $\mathrm{MG}_{1}$.

From Figure 16a,b, it is obvious that power transmission via MGs under Case 1 is less than that under Case 2. From Figure 16c, we see that power transmission between PG and MGs under Case 1 is larger than that under Case 2. The above results show the feasibility of the impact of different weights on the objective function.

\section{Conclusions}

In this paper, a class of novel robust and optimal controller design for a dynamical series-shaped EI system has been presented. The robustness and operation cost optimization of the EI system are considered simultaneously. A PSO algorithm is applied to optimize the parameters of the proposed controller. Simulations show the effectiveness of the proposed method. For our future research, more authentic and complicated EI scenarios will be the focus, and the system communication time delay will be taken into consideration.

Author Contributions: The work presented here was carried out through the cooperation of all authors. H.H. and J.C. conceived the scope of the paper; C.H. and Y.Q. conceived the analysis and performed the simulations; H.H. and C.H. wrote the paper; J.C. acquired the funding and performed revisions before submission. All authors read and approved the manuscript. 
Funding: This work was funded in part by the National Natural Science Foundation of China (Grant No. 61472200) and Beijing Municipal Science and Technology Commission (Grant No. Z161100000416004).

Conflicts of Interest: The authors declare no conflict of interest.

\section{Nomenclature}

BES

$D_{1}$

$D_{2}$

$D_{3}$

DEG

DER

EI

ER

$\mathrm{ER}_{1}$

$\mathrm{ER}_{2}$

$\mathrm{ER}_{3}$

ES

FC

FES

$\Delta f_{1}$

$\Delta f_{2}$

$\Delta f_{3}$

$\mathrm{HP}$

HT

$K_{D E G C}$

$K_{E S}$

$K_{E S C}$

$K_{F C}$

$K_{H P}$

$K_{H P C}$

$K_{M T}$

$K_{M T C}$

$K_{P H E V}$

$K_{P H E V C}$

LFC

$M_{1}$

$M_{2}$

$M_{3}$

MG

$\mathrm{MG}_{1}$

$\mathrm{MG}_{2}$

$\mathrm{MG}_{3}$

MT

PG

PHEV

PI

PSO

PV

$P_{B E S}$

$P_{D E G}$
Battery energy storage

Damping coefficient in $\mathrm{MG}_{1}$

Damping coefficient in $\mathrm{MG}_{2}$

Damping coefficient in $\mathrm{MG}_{3}$

Diesel engine generator

Distributed energy resource

Energy Internet

Energy router

Energy router in $\mathrm{MG}_{1}$

Energy router in $\mathrm{MG}_{2}$

Energy router in $\mathrm{MG}_{3}$

Electrolyzer

Fuel cell

Flywheel energy storage

Frequency deviation of $\mathrm{MG}_{1}$

Frequency deviation of $\mathrm{MG}_{2}$

Frequency deviation of $\mathrm{MG}_{3}$

Heat pump

Hydrogen tank

PI controllers of DEGs

Gain of ESs

PI controllers of ESs

Gain of FCs

Gain of HPs

PI controllers of HPs

Gain of MTs

PI controllers of MTs

Gain of PHEVs

PI controllers of PHEVs

Load-frequency control

Inertia constant in $\mathrm{MG}_{1}$

Inertia constant in $\mathrm{MG}_{2}$

Inertia constant in $\mathrm{MG}_{3}$

Microgrid

The first microgrid

The second microgrid

The third microgrid

Micro-turbine

Power grid

Plug-in hybrid electric vehicle

Proportional integral

Particle swarm optimization

Photovoltaic

Exchange power of BES

Output power of DEGs 


\begin{tabular}{|c|c|}
\hline$P_{E S}$ & Output power of ESs \\
\hline$P_{F C}$ & Output power of FCs \\
\hline$P_{F E S}$ & Exchange power of FES \\
\hline$P_{H P}$ & Output power of HPs \\
\hline$P_{L O A D 1}$ & Power consumption of load1 \\
\hline$P_{L O A D 2}$ & power consumption of load2 \\
\hline$P_{L O A D 3}$ & power consumption of load3 \\
\hline$P_{M T}$ & Output power of MTs \\
\hline$P_{P H E V}$ & Output power of PHEVs \\
\hline$P_{P V 1}$ & Output power of PV units in $\mathrm{MG}_{1}$ \\
\hline$P_{P V 3}$ & Output power of PV units in $\mathrm{MG}_{3}$ \\
\hline$P_{W T G 1}$ & Output power of WTGs in $\mathrm{MG}_{1}$ \\
\hline$P_{\text {WTG2 }}$ & Output power of WTGs in $\mathrm{MG}_{2}$ \\
\hline$\Delta P_{1}$ & Power deviation of $\mathrm{MG}_{1}$ \\
\hline$\Delta P_{2}$ & Power deviation of $\mathrm{MG}_{2}$ \\
\hline$\Delta P_{3}$ & Power deviation of $\mathrm{MG}_{3}$ \\
\hline$\Delta P_{E S}$ & Change of $P_{E S}$ \\
\hline$\Delta P_{E S C}$ & Control outputs of ESs \\
\hline$\Delta P_{F C}$ & Change of $P_{F C}$ \\
\hline$\Delta P_{M T}$ & Change of $P_{M T}$ \\
\hline$\Delta P_{M T C}$ & Control outputs of MTs \\
\hline RES & Renewable energy source \\
\hline$T_{B E S}$ & Time constants of BES devices \\
\hline$T_{D E G}$ & Time constants of DEGs \\
\hline$T_{E S}$ & Time constants of ESs \\
\hline$T_{F C}$ & Time constants of FCs \\
\hline$T_{F E S}$ & Time constants of FES devices \\
\hline$T_{H P}$ & Time constants of HPs \\
\hline$T_{P H E V}$ & Time constants of PHEVs \\
\hline$U_{D E G}$ & Control outputs of DEGs \\
\hline$U_{H P}$ & Control outputs of HPs \\
\hline$U_{P H E V}$ & Control outputs of PHEVs \\
\hline WTG & Wind turbine generator \\
\hline$K_{E R 12 C}$ & PI controller of transmission line between $M_{1}$ and $M_{2}$ \\
\hline$K_{E R 23 C}$ & PI controller of transmission line between $\mathrm{MG}_{2}$ and $\mathrm{MG}_{3}$ \\
\hline$P_{E R 12}$ & Power transmission between $\mathrm{MG}_{1}$ and $\mathrm{MG}_{2}$ \\
\hline$P_{E R 23}$ & Power transmission between $\mathrm{MG}_{2}$ and $\mathrm{MG}_{3}$ \\
\hline$P_{P G}$ & Power transmission between $\mathrm{PG}$ and $\mathrm{MG}_{1}$ \\
\hline$T_{E R 12}$ & Time constant of transmission line between $\mathrm{MG}_{1}$ and $\mathrm{MG}_{2}$ \\
\hline$T_{E R 23}$ & Time constant of transmission line between $\mathrm{MG}_{2}$ and $\mathrm{MG}_{3}$ \\
\hline$U_{E R 12}$ & Control output of transmission line between $\mathrm{MG}_{1}$ and $\mathrm{MG}_{2}$ \\
\hline$U_{E R 23}$ & Control output of transmission line between $\mathrm{MG}_{2}$ and $\mathrm{MG}_{3}$ \\
\hline
\end{tabular}

\section{References}

1. Bhattacharya, M.; Paramati, S.R.; Ozturk, I.; Bhattacharya, S. The effect of renewable energy consumption on economic growth: evidence from top 38 countries. Appl. Energy 2016, 162, 733-741. [CrossRef]

2. Bilgen, S.; Kaygusuz, K.; Sari, A. Renewable energy for a clean and sustainable future. Energy Sources 2004, 26, 1119-1129. [CrossRef]

3. Venkataramanan, G.; Marnay, C. A larger role for microgrids. IEEE Power Energy Mag. 2008, 6, 78-82. [CrossRef]

4. Kroposki, B.; Lasseter, R.; Ise, T.; Morozumi, S.; Papathanassiou, S.; Hatziargyriou, N. Making microgrids work. IEEE Power Energy Mag. 2008, 6, 40-53. [CrossRef] 
5. Mathiesen, B.V.; Lund, H.; Connolly, D.; Wenzel, H.; Østergaard, P.A.; Möller, B.; Nielsen, S.; Ridjan, I.; Karnøe, P.; Sperling, K.; et al. Smart energy systems for coherent 100\% renewable energy and transport solutions. Appl. Energy 2015, 145, 139-154. [CrossRef]

6. Sreedharan, P.; Farbes, J.; Cutter, E.; Woo, C.; Wang, J. Microgrid and renewable generation integration: University of California, San Diego. Appl. Energy 2016, 169, 709-720. [CrossRef]

7. Odun-Ayo, T.; Crow, M.L. Structure-preserved power system transient stability using stochastic energy functions. IEEE Trans. Power Syst. 2012, 27, 1450-1458. [CrossRef]

8. Olivares, D.; Mehrizi-Sani, A.; Etemadi, A.; Canizares, C.; Iravani, R.; Kazerani, M.; Hajimiragha, H.A.; Gomis-Bellmunt, O.; Saeedifard, M.; Palma-Behnke, R.; et al. Trends in microgrid control. IEEE Trans. Smart Grid 2014, 5, 1905-1919. [CrossRef]

9. Chakrabortty, A.; Ilić, M.D. Control and Optimization Methods for Electric Smart Grids; Springer: New York, NY, USA, 2012.

10. Rifkin, J. The Third Industrial Revolution: How Lateral Power Is Transforming Energy, the Economy, and the World; Palgrave Macmillan: New York, NY, USA, 2013; pp. 31-46.

11. Cao, J.; Yang, M. Energy Internet-Towards smart grid 2.0. In Proceedings of the Fourth International Conference on Networking \& Distributed Computing, Los Angeles, CA, USA, 21-24 December 2013; pp. 105-110.

12. Tsoukalas, L.H.; Gao, R. From smart grids to an energy Internet-assumptions, architectures and requirements. Smart Grid and Renew. Energy 2009, 1, 18-22.

13. Han, X.; Yang, F.; Bai, C.; Xie, G.; Ren, G.; Hua, H.; Cao, J. An open energy routing network for low-voltage distribution power grid. In Proceedings of the 1st IEEE International Conference on Energy Internet, Beijing, China, 17-21 April 2017; pp. 320-325.

14. Geidl, M.; Koeppel, G.; Favre-Perrod, P.; Klokl, B. Energy hubs for the futures. IEEE Power Energy Mag. 2007, 5, 24-30. [CrossRef]

15. Boyd, J. An internet-inspired electricity grid. IEEE Spectr. 2013, 50, 12-14. [CrossRef]

16. Wu, J.; Guan, X. Coordinated multi-microgrids optimal control algorithm for smart distribution management system. IEEE Trans. Smart Grid 2013, 4, 2174-2181. [CrossRef]

17. Niknam, T.; Azizipanah-Abarghooee, R.; Narimani, M.R. An efficient scenario-based stochastic programming framework for multi-objective optimal micro-grid operation. Appl. Energy 2012, 99, 455-470. [CrossRef]

18. Elrayyah, A.; Cingoz, F.; Sozer, Y. Construction of nonlinear droop relations to optimize islanded microgrid operation. IEEE Trans. Ind. Appl. 2015, 51, 3404-3413. [CrossRef]

19. Zheng, X.; Li, Q.; Li, P.; Ding, D. Cooperative optimal control strategy for microgrid under grid-connected and islanded modes. Int. J. Photoenergy 2014, 2014, 1-11. [CrossRef]

20. Zhao, J.; Dörfler, F. Distributed control and optimization in DC microgrids. Automatica 2015, 61, 18-26. [CrossRef]

21. Bevrani, H.; Feizi, M.R.; Ataee, S. Robust frequency control in an islanded microgrid: $H_{\infty}$ and $\mu$-Synthesis approaches. IEEE Trans. Smart Grid 2016, 7, 706-717. [CrossRef]

22. Baghaee, H.R.; Mirsalim, M.; Gharehpetian, G.B.; Talebi, H.A. A generalized descriptor-system robust $H_{\infty}$ control of autonomous microgrids to improve small and large signal stability considering communication delays and load nonlinearities. Int. J. Electr. Power Energy Syst. 2017, 92, 63-82. [CrossRef]

23. Hua, H.; Cao, J.; Yang, G.; Ren, G. Voltage control for uncertain stochastic nonlinear system with application to energy Internet: non-fragile robust $H_{\infty}$ approach. J. Math. Anal. Appl. 2018, 463, 93-110. [CrossRef]

24. Singh, V.P.; Mohanty, S.R.; Kishor, N.; Ray, P.K. Robust H-infinity load frequency control in hybrid distributed generation system. Int. J. Elect. Power Energy Syst. 2013, 46, 294-305. [CrossRef]

25. Hua, H.; Qin, Y.; Cao, J. A class of optimal and robust controller design for islanded microgrid. In Proceedings of the IEEE 7th International Conference on Power and Energy Systems, Toronto, ON, Canada, 1-3 November 2017; pp. 111-116.

26. Baghaee, H.R.; Mirsalim, M.; Gharehpetian, G.B.; Talebi, H.A. A decentralized robust mixed $H_{2} / H_{\infty}$ voltage control scheme to improve small/large-signal stability and FRT capability of islanded multi-DER microgrid considering load disturbances. IEEE Syst. J. 2017, 1-12.

27. Vachirasricirikul, S.; Ngamroo, I. Robust LFC in a smart grid with wind power penetration by coordinated V2G control and frequency controller. IEEE Trans. Smart Grid 2014, 5, 371-380. [CrossRef] 
28. Shayeghi, H.; Jalili, A.; Shayanfar, H.A. A robust mixed $H_{2} / H_{\infty}$ based LFC of a deregulated power system including SMES. Energy Convers. Manag. 2008, 49, 2656-2668. [CrossRef]

29. Ngamroo, I. Robust coordinated control of electrolyzer and PSS for stabilization of microgrid based on PID-based mixed $\mathrm{H}_{2} / \mathrm{H}_{\infty}$ control. Renew. Energy 2012, 45, 16-23. [CrossRef]

30. Farsangi, M.M.; Song, Y.H.; Tan, M. Multi-objective design of damping controllers of FACTS devices via mixed $\mathrm{H}_{2} / \mathrm{H}_{\infty}$ with regional pole placement. Int. J. Elect. Power Energy Syst. 2003, 25, 339-346. [CrossRef]

31. Kennedy, J.; Eberhart, R. Particle swarm optimization. In Proceedings of the IEEE International Conference on Neural Networks, Perth, Australia, 27 November-1 December 1995; pp. 1942-1948.

32. Li, X.; Song, Y.J.; Han, S.B. Study on power quality control in multiple renewable energy hybrid microgrid system. In Proceedings of the 2007 IEEE Lausanne Power Tech, Lausanne, Switzerland, 1-5 July 2007; pp. 2000-2005.

33. Vachirasricirikul, S.; Ngamroo, I. Robust controller design of heat pump and plug-in hybrid electric vehicle for frequency control in a smart microgrid based on specified-structure mixed $\mathrm{H}_{2} / \mathrm{H}_{\infty}$ control technique. Appl. Energy 2011, 88, 3860-3868. [CrossRef]

34. Gu, D.W.; Petkov, P.H.; Konstantinov, M.M. Robust Control Design with MATLAB; Springer: New York, NY, USA, 2005.

35. Jiang, Z.P.; Teel, A.R.; Praly, L. Small-gain theorem for ISS systems and applications. Math. Control Signals Syst. 1994, 7, 95-120. [CrossRef]

36. Ho, S.J.; Ho, S.Y.; Hung, M.H.; Shu, L.S.; Huang, H.L. Designing structure-specified mixed $H_{2} / H_{\infty}$ optimal controllers using an intelligent genetic algorithm IGA. IEEE Trans. Control Syst. Technol. 2005, 13, 1119-1124.

37. Carpinelli, G.; Mottola, F.; Proto, D. A multi-objective approach for microgrid scheduling. IEEE Trans. Smart Grid 2017, 8, 2109-2118. [CrossRef]

(C) 2018 by the authors. Licensee MDPI, Basel, Switzerland. This article is an open access article distributed under the terms and conditions of the Creative Commons Attribution (CC BY) license (http:/ / creativecommons.org/licenses/by/4.0/). 